\section{The current climate}

\section{Stefan Rahmstorf}

$\mathrm{H}$ ow are ocean currents caused, and how do they affect climate? These questions were hotly debated in the nineteenth century. Some argued that water is simply pushed along by the wind; others postulated 'convection currents' caused either by heating and cooling or by evaporation and precipitation. Even today, the driving forces and climatic effects of ocean currents are still not completely understood.

In 1908, Johan Sandström laid the foundations of our modern understanding of ocean currents with a series of classic experiments carried out at Bornö oceanographic station in Sweden. He filled a small tank with water layers of different densities from an adjacent fjord and then blew air over the surface and/or heated and cooled the fluid at different levels. He thus elucidated the properties of 'wind-driven' and 'thermal' circulation. The latter term was amended by the 1920 s to 'thermohaline circulation', because water density in the ocean is determined by both temperature and salinity.

Sandström found that thermal forcing can give rise to a steady circulation only if heating occurs at a greater depth than cooling - a fact that is familiar to oceanography students as 'Sandström's theorem'. But 'thermohaline forcing' - that is, fluxes of heat and freshwater - occurs only at the ocean's surface, except for a small contribution from geothermal heating

So what is the deep heat source that drives the ocean's observed thermohaline circulation? Sandström recognized that it is the

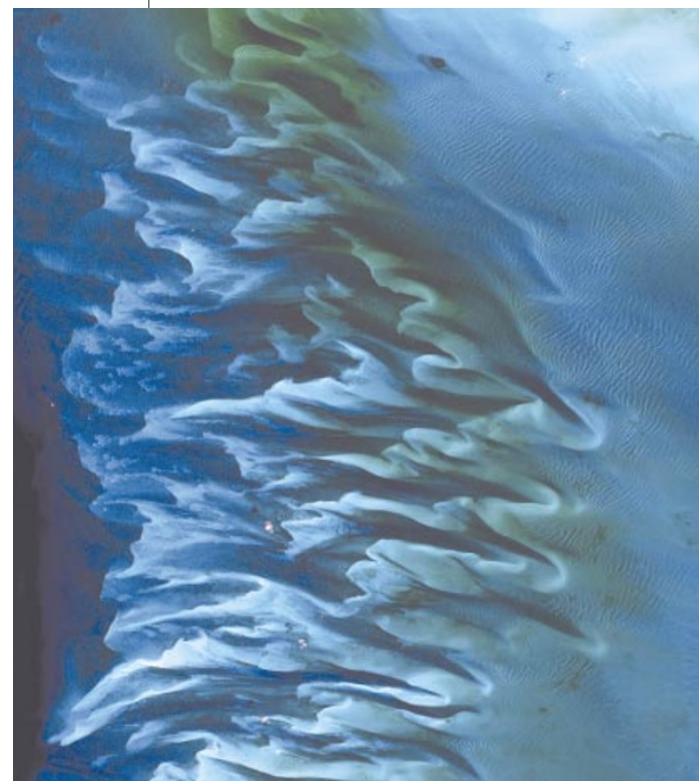

Wave review: ocean currents sculpted these sand and seaweed formations, dozens of miles across. downward penetration of heat at lowlatitudes, due to turbulent mixing, that provides this thermal engine. His speculation that salinitydriven convection causes the low-latitude mixing was wrong, however - turbulent mixing is instead powered by winds and tides. Thermohaline circulation is thus caused by the joint effect of thermohaline forcing and turbulent mixing - it can be defined as currents driven by fluxes of heat and freshwater across the sea surface and subsequent interior mixing of heat and salt. Although winds and tides are important in creating turbulence, this driving mechanism is clearly distinct from winddriven circulation: thermohaline circulation requires thermohaline surface forcing, whereas wind-driven circulation does not.

To complicate matters, the ocean's density distribution, which determines pressure gradients and thus circulation, is itself affected by currents and mixing of any kind. Thermohaline and wind-driven currents cannot therefore be separated by oceanographic measurements. There are thus two distinct forcing mechanisms, but not two separate circulations. Change the wind stress, and the thermohaline circulation will change; alter thermohaline forcing, and the wind-driven currents will also change. It is because of thermohaline forcing that wind-driven currents are relegated to the upper ocean - in unstratified water they would extend to the bottom.

But although thermohaline circulation is not measurable, the concept is still a useful one, and modern computer models of oceans can be used to carry out experiments (not unlike those of Sandström with real water) to study the properties of these currents. In these models, different surface forcing fields can be prescribed, and by designating the surface wind-stress as zero, a purely thermohaline circulation can be computed. The required turbulent mixing can be varied independently from the surface wind stress, as they appear in different terms of the hydrodynamic equations. The resulting zonally integrated circulation is essentially similar to the circulation obtained with wind-stress forcing, but lacks the wind-driven cells known as Ekman cells (which consist of surface water that is pushed along by the wind and returns within the upper few hundred metres of the ocean).

In this sense, zonally integrated streamlines can be interpreted as a superposition of wind-driven and thermohaline components, much as Sandström interpreted his tank experiments. On the other hand, when wind stress remains constant, the vertically integrated circulation looks similar with or without thermohaline forcing, with the exception of the Antarctic Circumpolar Current.

Wind-driven and thermohaline circula-

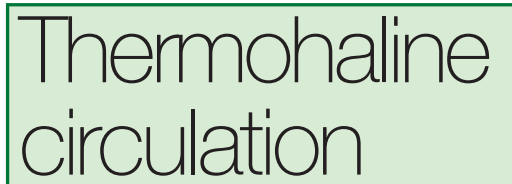

Heat and freshwater fluxes at the ocean's surface play a key role in forming ocean currents, which in turn have a major effect on climate.

tions can thus be disentangled to some extent by models, which helps us understand what aspects of the circulation are linked to what surface boundary conditions. This is useful in analysing the effect of a change in forcing, such as a freshwater influx, on currents - a typical problem in palaeoclimate studies, in which sediment data suggest that freshwater influx has caused major changes in currents in the past. It is also highly relevant when considering the ocean's response to global warming, because evaporation, precipitation and runoff are expected to increase in a warmer world.

How strongly might changes in thermohaline circulation affect climate? To what extent do Europe's mild winters depend on the transport of heat by the Gulf Stream and North Atlantic Current? Simulations in which the ocean's heat transport is switched off consistently show a large winter cooling over the northern Atlantic and adjacent land areas, reaching several degrees in inland Europe, up to $10^{\circ} \mathrm{C}$ over Greenland and even exceeding $20^{\circ} \mathrm{C}$ over the Nordic seas. This heat transport warms the climate on both sides of the Atlantic, and is therefore not the main reason that Europe is warmer than Newfoundland - this phenomenon is mainly due to the prevailing winds in the two regions. But ocean currents do make the northern Atlantic much warmer than at comparable latitudes in the northern Pacific. Changes in these currents are our best explanation for the abrupt and marked climate swings that occurred over the north Atlantic many times during the most recent glacial period, as shown by Greenland's ice cores and by deep-sea sediments. Circulation changes might again be triggered by global warming.

Despite its known limitations, the concept of a thermohaline ocean circulation remains well defined and useful. Understanding its past and future behaviour is crucial to our understanding of climate change.

Stefan Rahmstorf is at the Potsdam Institute for Climate Impact Research, Box 601203,

14412 Potsdam, Germany.

\section{FURTHER READING}

Rahmstorf, S. Nature 419, 207-214 (2002).

Seager, R. et al. Q. J. R. Meteorol. Soc. 128, 2563 (2002). Vellinga, M. \& Wood, R. A. Clim. Change 54, 251-267 (2002).

Wunsch, C. Nature 405, 743-744 (2000). 